some slight degree, and they may contain natural antiendotoxins. But they seem to act chiefly as leucocytic stimulants, inducing a hage outflow of cells, whose function is to protect the body from infection.

Floyd and Lucas: Jourm. BrBLIOGRAPH

Med. Research, September, 1909 Hiss and Zinsser, Journ. Med. Research, February, 1908; February.

Kling: Z Zitschr. f. Immunitätsforsch., Original Bd. VII, Heft 2. Korschun: Ann. de l'Instit. Pasteur, July, 1908.

Lambert: Amer. Journ. Med. Sci., vol. 137.

Opie: Quoted by Floyd and Lucss

Zeitsch Centralbl. fuir Bakt; Bd. 35, 36, 39, 40, 42, 45, 46, 50, 53, 54 Zeitschr, f. Im

Watabiki : Journ. Infectious Diseases, June, 1909.

\section{ELECTRICITY IN NEURASTHENIA**}

BY JAMES METCALFE, M.D.

HONORARY SURGEON, ST. OATHERINE'S HOME FOR OANCER AND INCURABLES, BRADFORD.

I wIsH to bring before you the uses of some forms of electrical applications in the treatment of neurasthenia. Bat belore doing 80 it is necessary to consider for a few minutes what is generally meant by nenrasthenia. It is difficult in a few terse sentences to define this disease. The term has been applied so widely and to such various and varied symptoms that it would be impossible to discuss it exhaustively in the time at my disposal. Bat I will take the main symptoms as they have exhibited themselves in the cases I have had to treat. These may be general, or local, or a combination of both. The patients are usually irritable or depressed. They are very anxious and consider their condition as extremely dangerous to life. They frequently are in dread of becoming insane. Sometimes the brain appears to be too active, and they are constantly pestered by all kinds of possible and impossible problems presenting themselves to their imagination day and night. They dread meeting people; they fear they are victims to some imaginary disease. They are frequently worried and are annoyed by the veriest trifles. Everything is a cause of complaint. They are great egoists and feel compelled to discuss their troubles with every patient listener. Many of them sleep badly-in fact, insomnia is one of the most trying symptoms of the disease. They suffer from flushes and fallness in the head and sometimes severe headaches. Frequently there is a sense of oppression in the chest and difficulty of breathing. Tachycardia is common, and the patient believes he or she is suffering from severe heart disease. Many suffer from gastro-intestinal neurasthenia. Feelings of distension, noisy eractations, borborygmi, and gurgling are complained of. Anorexia is usual. There is often aching in the eyes and neuralgic pains in the head. Spinal oymptoms are common-localized pains in the back, disturbances of sensation, and intercostal pains. In some cases there are pains in the extremities. The word that probably sums up the condition of the patient more than any other is-emotional.

The conditions which might be confused with neurasthenia are melancholia in which there are actual delusions, and hysteria in which there are marked hysterical paroxysms. Of course, tabes and general paralysis might also exhibit some of the symptoms mentioned-in their early stages, at any rate.

There is apparently no discoverable morbid anatomy in these cases, bat there is undoubtedly a pathology. Hypertension appears to be a trequent concomitant, or perhaps a cause of the disease. According to Gay, the presence in the blood of alimentary toxins, generally acid and with a vaso-constrictor effect, and the retention of extraotive substances of the xantho-aric series will cause hypertension. I believe, too, that a rigidity of the walls of the vessels set up by some central irritation of the nervous system is often present, and is a cause of a large number of the subjective symptoms. I bave noticed, too, that this hypertension is not so readily observed by examination of the palse as one would have thought. On examining the pulse of several neurasthenic patients the impression gained was that the pulses

\footnotetext{
*A paper read before the Bradford Medico-Chirurgical Society.
} January I7th, 1911 . were not high tension, but the sphygmomanometer usually revealed a considerable amount of hypertension. The point I am anxious to show is this: That the symptoms declined pari passu with a decrease in the sphygmomanometric readings until, if the latter could be reduced to nearly normal, the patient became well.

I am not now concerned with the usual methods of treating neurasthenia. The cases I have had in hand have all received skilful medical treatment before they were sent to me. One or two had had Weir Mitchel treatment, in which, of course, a certain amount of electrical energy is used. The currents I have treated these cases with have been those known as high frequency, or d'Arsonvalization; or, as an alternative, static electricity produced by a Wimshurst machine. I may say, as a rule, that where the nearasthenia has been associated with marked metabolio deficiency, or of the gastro-intestinal type, I have found high frequency currents the most effective; but if the symptoms pointed more to a condition of a pure neurosis, I have observed that static electricity produces the best results. (Here followed a description, with illustrations, of the high frequency and static machines used.)

I wish to draw attention to a few cases treated by these mothods during the last fow years. I will not record a large number, because they give, to a great extent, a mere recapitalation of the same class of disease. I think I may say that in most cases the results of treatment have been permanent :

1. Unmarried woman, aged 46. Gastro-intestinal neurasthenia, flatulency, tachycardia, panophobia ; ill six months. Received auto-condensation high frequency on the couch thrice weekly from April 7th, 1904, to May 13th. Cured.

2. Lady, aged 36. Insomnia, restlessness, depressed; great fear of railway travelling (sidero-dro-mophobia); pains in limbs and in breasts; ill many month

general static electricity. Cured. 3. Gentleman, aged 38. Depression, insomnia, distension of stomach, flatulency; ill for more than twelve months. Had been treated, in addition to ordinary methods, previously by
light baths and Weir Mitchell treatment. Received 300 to 500 milliampères of suto-condensation for half an hour at a time and a few minutes' application of a glass vacuum electrode nver stomsch. Attended eighteen times between June 14th, 1907, and July 31st. Cured, and has remained so.

4. Mr. P. aged 35. Remarkable case. Began with nervous symptoms in 190 ; always frightened, dreading what he could not describe; constantly thinking in bed; pain in head, with fallness mostly at back of hesd; slways burning pains in stomach and sense of distension; bowels somewhat loose terrible insomnia, had never slept more than an hour or so consecutively for years. Had nineteen applications of antocondensation, 400 to 800 milliampères of current, for half an hour at a time, and local glass electrodes to stomach, head, and hoir Biod tension, socording to the Riva-Rocci, on first spine. Blood tension, sccording to the Riva-Rocci, on frrst treatment, 190 ; at end of treatment only 120 to

has remained perfectly well for over two years.
. Miss $S$., aged 25. Nervous, depressed, insomnia, etc., many months. Twelve applications static electricity. Cured.

6. Mr. W., aged 39. Twelve months before treatment began to lose appetite, conld not sleep, and always tired; gets horribly depressed, sometimes feeling slmost suicidel ; bowels sometimes constipated, sometimes loose; very irritable. Treated by high frequency anto-condensation and glass vacuum electrode to stomach and head. Remained cured over two years.

7. Gentleman, aged 59. More or less insomnia four or five years. Aching pains and fullness in the head; some distensinn and flatulency; insomnia now constant; arterial tension 180 Had twelve and a half hours' applications of anto-condensation and local electrodes to head and stomsch. Now sleeps sonndly, and arterial tension 120 to 130 , and feels quite well.

8. Lady, aged 33. Very nenrotic; complains of her head, 8. Lady, aged 33. Very nenrotic ; complains of her head,
difficulty of breathing, and sobbing respiration; ovarian neuralgia ; constant insomnis; blood tension 160. After twelve applications of static bath slept perfectly, and difficulty of breathing, etc., disappeared. Blood tension reduced to 120 .

I do not wish it to appear that every case of neurasthenia treated electrically is cured, nor do I suggest that every case of neurasthenia should receive this form of treat. ment. A large number of cases treated by $r \in s t$, fresh air, drugs, and other methods, recover. But the cases I have quoted had been treated by the usual methods by the practitioners who referred them to me. They have been obstinate, obdurate-conditions not amenable to the usnal remedies. Neurasthenia is a condition frequently seen by every general practitioner, and the anxiety this class of case gives him appears ont of all proportion to the seriousness of the disease. I think it well to remember that when all other methods fail there is still a possibility of effecting a cure. 
It will naturally be asked, How do the electrical currents act physiologically so as to cause the improvement as seen in this class of case? Psychical effects may be produced at times by these methods, as may happen in every other form of treatment. But improvement and care must in a series of cases be due, as in other methods, to powerfal therapeatical effects.

In cases in which the blood pressure is high, as I have already mentioned, the effect of reduction of arterial tension may in itself produce the result. In the use of electrical machines there is always a large amount of ozone generated, and it is not impossible that the inhalation of this gas for half an hour at a time may have some power of improving the patient's condition.

D'Arsonval and others have demonstrated increased tissue changes, more rapid reduction of the oxyhaemo. globin in the blood and increased elimination of waste products in the urine. Not only the sympathetic nerves controlling the vasomotor system, bat also those controlling the secretory, the thermogenic, and the peristaltic functions, are stimulated. There is a profound action on the protoplasm of cells everywhere, increasing their chemical changes. Usually an increased amount of urea is excreted, attended by a disappearance of uric acid showing the oxidation of nitrogenous material. It is said that the output of $\mathrm{CO}_{2}$ is sometimes increased from 17 to 37 litres an hour, and that there may be an increase in heat projuction from 79 to 127 calories an hour.

\section{SIMULATED DISEASE}

\section{OCCURRING IN PERSONS OF HYSTERICAL OR NEUROTIC TEMPERAMENT.}

By JOHN EWENS, L R.C.P.LOND., L.R C.S.EDIN., CONSULTING SURGEON TO THE BRISTOL ROYAL HOSPITAL FOR WOMEN AND CHIIDREN.

THE very interesting case of "dermatitis artefacta" reported by Dr. Adamson in the Journal of Jaly 2nd, 1910, recalls to my memory some cases occurring in a considerably long practice which have, I think, a practical bearing on the perplexing difficulties frequently experienced by most medical men in the treatment of certain anomelous cases, which from peculiar family or other circumstances, where the patient or relatives have reasons for simulating indisposition, and from motives of shame or false delicacy wish to conceal the tricks practised, thereby involving the practitioner inexperienced in such matters in mach trouble, fearing to give offence to relatives, therefore hesitating to express an opinion as to the fraud or unworthy motive on the part of the patient. It requires considerable moral courage on the part of the medical man to face the difficulty, and it is always necessary to guard oneself at every point to avoid hinting at a suspicion which may prove unfounded. A mistake would almost certainly involve the loss of the patient, and possibly ruin the prospects of a young practitioner. Two of the following cases (Nos. II and III) will illastra te the difficulty; but having once clearly and satisfactorily to oneself, from irrefutable evidence, proved the nature of the case, no hesitation should be felt as to the duty of prompt and decisive action. The natural reluctance to say anything which may cause unpleasant feelings between members of a family, or a rapture of the proper relations which should exist between a medical man and his patients, may well cause hesitation in forcing home his suspicions as to fraud or other unworthy motive; but in this as well as all other professional relations, the trite maxim, "Honesty is the best policy," should gaide the members of our noble profession, and will in the end bring most credit, as well as a clear conscience in the faithful performance of daty. I trust the report of the following cases may be helpfal to my younger and possibly less experienced professional brethren, and act as a guide to them in dealing with cases involving delicacy and accuracy in diagnosis.

CASE I.-The first case occurred in my very early practice more than fifty years since, and at this distance of time exact details are wanting, bat the main facts still remain impressed forcibly on my mind. An unmarried womsn, aged 30 years, of healthy family, after an easy extraction of a lower molar tooth complained of stiffness of the jaw and inability to masticate properly and swallow any solid food. The stiffness steadily increased, efforts to force the jaw open by wedges absolutely failing. Being of a neurotic and anaemic temperament, tonics, iron, nax vomica, etc., were freely administered with aperients, mild electrical shocks were frequently given, without $\epsilon$ ffect. No solid food was taken, but she freely partook of fluid nourishment. In order to discover any impediment to opening the mouth I placed her fully under chloroform, and thus established the absence of ossific or other mischief about the joint, but as she was emerging from anaesthesia, a series of hystero-epileptic attacks occurred, lasting for two hours, effectually preventing my repeating the experiment.

The next phase of the complaint presented itself in the form of pseudo-laryngitis, apparently originating in the form of an ordinary cold, resulting in loss of voice, with occasional spasmodic breathing, the patient generally speaking in a low voice or whisper. This continued for many years, in fact, for the twenty.five years during which I had the opportunity of knowing ber personally. She never, I believe, thoroughly recovered her voice.

The next development was simulated peritonitis with obstinate constipation, easily diagnosed as another form of the hysterical nature of the case. It was followed by retention of urine, requiring the ase of the catheter three times daily. On leaving the village to reside at a distance of three miles, I explained that I could not possibly give the necessary attention, and that I would teach her mother to use the catheter. She shortly passed urine voluntarily, and no further trouble of that kind occurred, conclusively proving the nature of the case. The next manifestation was an attack of apparent apoplexy. I was hastily summoned to her early one morning, and found her surrounded by weeping relatives, who said she had an apoplectic fit. She lay passive, her eyes partially open, pupils somewhat dilated, breathing normal, no stertor. no power to swallow fluids when placed in her mouth. The parents had found her thus early in the morning, and could not account for the attack, as she had been as usual daring the previous day, and went to bed well. Reflex movements of the legs were totally absent, tickling the soles of the feet eliciting no response. (This was the more forcibly impressed upon me as I went from her house to see a young woman actually dying of apoplexy in whom the reflex was very marked.)

My previous experience of the case led me to take a very optimistic view, and in a very decided and lond tone I told the parents, who at the time thought me very unkind, that they need not be troubled, as I felt sure she would quite recover within twenty-four hours. I have no doubt she heard me, and was influenced by my very decided manner and opinion. Next morning all the symptoms had disappeared, and she was soon as well as usual. I am not aware that any serious manifestation of hysteria ever occurred afterwards. This case was extremely difficalt to explain, no adequate motive existing, and nothing material could be gained by imposition except the incident of retention of urine, which is no doubt often due to a perversion of the moral faculties in hysterical young women, and ceases when unable to get a catheter passed. The parents were of the labouring class, and not likely to encourage deception. The uterine functions were normally performed.

CASE II -A young gentleman, aged 16, was brought to mo complaining of gastric trouble, with pain attributed to liver disease. It was stated that an uncle or grandfather had suffered from cancer of the liver, but of this there was no definite evidence. He was the son of a farmer in good position and easy circumstances. He had refused for some time to take food and eat as the other members of the family, yet did not lose flesh or show any appreciable signs of disease. He was ordered milk diet, but declared he could not take it. His home being at a large dairy farm, milk was easily obtained, and, failing emasiation or other signs of disease, I had no doubt that he secretly got access to the dairy, but I could not prove it. Home treatment being useless for obvious reasons, I suggested his retarning to school in Bristol ander my care, and judicious surveillance. Convinced that he was only pretending not to be able to take food, I took the mistress of the school into my confidence, telling her my suspici ons. I ordered 